\title{
COVID-19 pandemic: challenges ahead
}

\author{
Horacio Márquez-González¹, María G. Miranda-Novales², Fortino Solórzano-Santos³, \\ Miguel Klunder-Klunder ${ }^{4}$, Juan Garduño-Espinoza ${ }^{5}$, and Jorge F. Méndez-Galván6*
}

${ }^{1}$ Departamento de Investigación Clínica, Hospital Infantil de México Federico Gómez; ${ }^{2}$ Unidad de Investigación de Análisis y Síntesis de Evidencia, Centro Médico Nacional, Siglo XXI, Instituto Mexicano del Seguro Social; ${ }^{3}$ Unidad de Investigación en Enfermedades Infecciosas, Hospital Infantil de México Federico Gómez; ${ }^{4}$ Subdirección de Gestión de la Investigación, Hospital Infantil de México Federico Gómez; ${ }^{5}$ Dirección de Investigación, Hospital Infantil de México Federico Gómez; ${ }^{6}$ Unidad de Investigación en Enfermedades Emergentes, Hospital Infantil de México Federico Gómez. Mexico City, Mexico

\begin{abstract}
Since December 2019, health systems worldwide have faced the pandemic caused by the new severe acute respiratory syndrome coronavirus 2. The pandemic began in China and has spread throughout the world. This new coronavirus has a high transmission capacity and elevated lethality in people over 60 years old and in those with risk factors (obesity, diabetes, and systemic arterial hypertension); those characteristics have a different proportion in each country. At present, there is no specific, effective, and safe treatment to treat this virus. In this review, an analysis is made on the differences in epidemiological aspects of the disease and its presentation in pediatric patients; the poorly-based recommendation for using an empirical combination of antimalarials plus antimicrobials as antiviral treatment; the indication of intravenous steroids; and the possible influence of antihypertensive drugs on the course of the disease.
\end{abstract}

Key words: Coronavirus 2019 disease. Severe acute respiratory syndrome coronavirus 2. Hydroxychloroquine. Azithromycin. Steroids. Angiotensin-converting enzyme-2.

\section{Pandemia de COVID-19: retos por enfrentar}

\section{Resumen}

A partir de diciembre de 2019, los sistemas de salud de todos los países se han enfrentado a la pandemia causada por un nuevo coronavirus (SARS-CoV-2), el cual fue notificado por primera vez en China y se ha esparcido por todo el mundo. Este nuevo coronavirus posee una alta capacidad para transmitirse. A escala mundial la letalidad ha sido más alta en la población mayor de 60 años y en aquellos que tienen factores de riesgo (obesidad, diabetes e hipertensión arterial sistémica). Sin embargo, estas características varían en proporción en cada país. Hasta el momento no hay un tratamiento específico, eficaz y seguro para combatir este virus. En este artículo se realiza un análisis sobre las diferencias globales en los aspectos epidemiológicos y con relación a su presentación en pacientes pediátricos, así como de la recomendación, con pobre fundamento, del uso de la combinación de antimaláricos y antimicrobianos empíricos como antivirales. También se analizan la indicación de esteroides intravenosos y la posible influencia de los fármacos antihipertensivos en el curso de la enfermedad.

Palabras clave: COVID-19. SARS-CoV-2. Hidroxicloroquina. Azitromicina. Esteroides. Enzima convertidora de angiotensina-2.

\section{Correspondence:}

*Jorge F. Méndez-Galván

E-mail: jorge.f.mendez@gmail.com

Available online: 14-09-2020

Date of reception: 18-06-2020

Date of acceptance: 25-06-2020

DOI: 10.24875/BMHIM.20000166
Bol Med Hosp Infant Mex. 2020;77(5):242-251

www.bmhim.com 1665-1146/@ 2020 Hospital Infantil de México Federico Gómez. Published by Permanyer. This is an open access article under the CC BY-NC-ND license (http://creativecommons.org/licenses/by-nc-nd/4.0/). 
Introduction

\section{Epidemiology of COVID-19 and its possible impact on the pediatric population}

Coronavirus 2019 disease (COVID-19) is an emerging zoonotic condition in which a virus from a wild animal broke the species barrier, passed to humans, and then established human-to-human transmission'.

At least four coronaviruses (CoV) that affect humans and cause mild to moderate flu-like illness have been described. The other three CoV cause severe diseases, such as severe acute respiratory syndrome CoV (SARSCoV), identified in 2003, which caused about 8000 cases with a 10\% lethality. In 2013, Middle East respiratory syndrome CoV (MERS-CoV) appeared, which had a lethality of more than $30 \%$. Finally, in December 2019, a new CoV was identified, SARS-CoV-2, which is causing a pandemic with $7 \%$ lethality. This new virus has different biological and epidemiological characteristics from the other two CoVs that cause severe disease ${ }^{2}$.

\section{SARS-CoV-2}

CoVs belong to the Nidovirales order of the Coronaviridae family and Coronaviridae subfamily, which contain a large RNA (ranging from 25 to $33 \mathrm{~kb}$ ) and comprise four genera phylogenetically named $\alpha, \beta, \gamma$, and $\delta$. CoVs affect many animals as well and are considered to have evolved from a CoV hosted in bats. Some of these CoVs, specifically of the genera $\alpha$ and $\beta$, affect humans and can cause mild to moderate influenza-like illness, as well as severe and fatal forms (Fig. 1) . $^{3}$

To date, seven CoVs are known to affect humans: two belong to the genus $\alpha$ CoVs (HCoVs-NL63 and HCoVs$229 \mathrm{E})$, and five to the genus $\beta$ CoVs, known as HCoVs-OC43, HCoVs-HKU, SARS-CoV, MERS-CoV, and the recently discovered SARS-CoV-2 ${ }^{4}$.

Among the $\beta$ CoVs, SARS-CoV, which causes a SARS, MERS-CoV, which causes MERS, and the recently discovered SARS-CoV-2, which causes COVID-19, stand out for causing severe disease to humans. SARS-CoV-2 shares nucleotides in different proportions with other $\mathrm{CoVs}^{5}$ (Fig. 2).

SARS-CoV-2 is a positive-stranded RNA virus, which has a diameter of $\approx 100 \mathrm{~nm}$, an approximate volume of $\sim 10^{6} \mathrm{~nm}^{3}=10^{-3} \mathrm{fL}$, and a mass of $\sim 103 \mathrm{MDa} \approx 1 \mathrm{fg}$. It has a membrane protein $\approx 2000$ copies per virion, envelope proteins $\approx 20$ copies, and spikes $\approx 10 \mathrm{~nm}$ and $\approx 100$ copies. The structure of SARS-CoV-2 shows some spikes or peaks that give the appearance of a surrounding crown (Fig. 3).

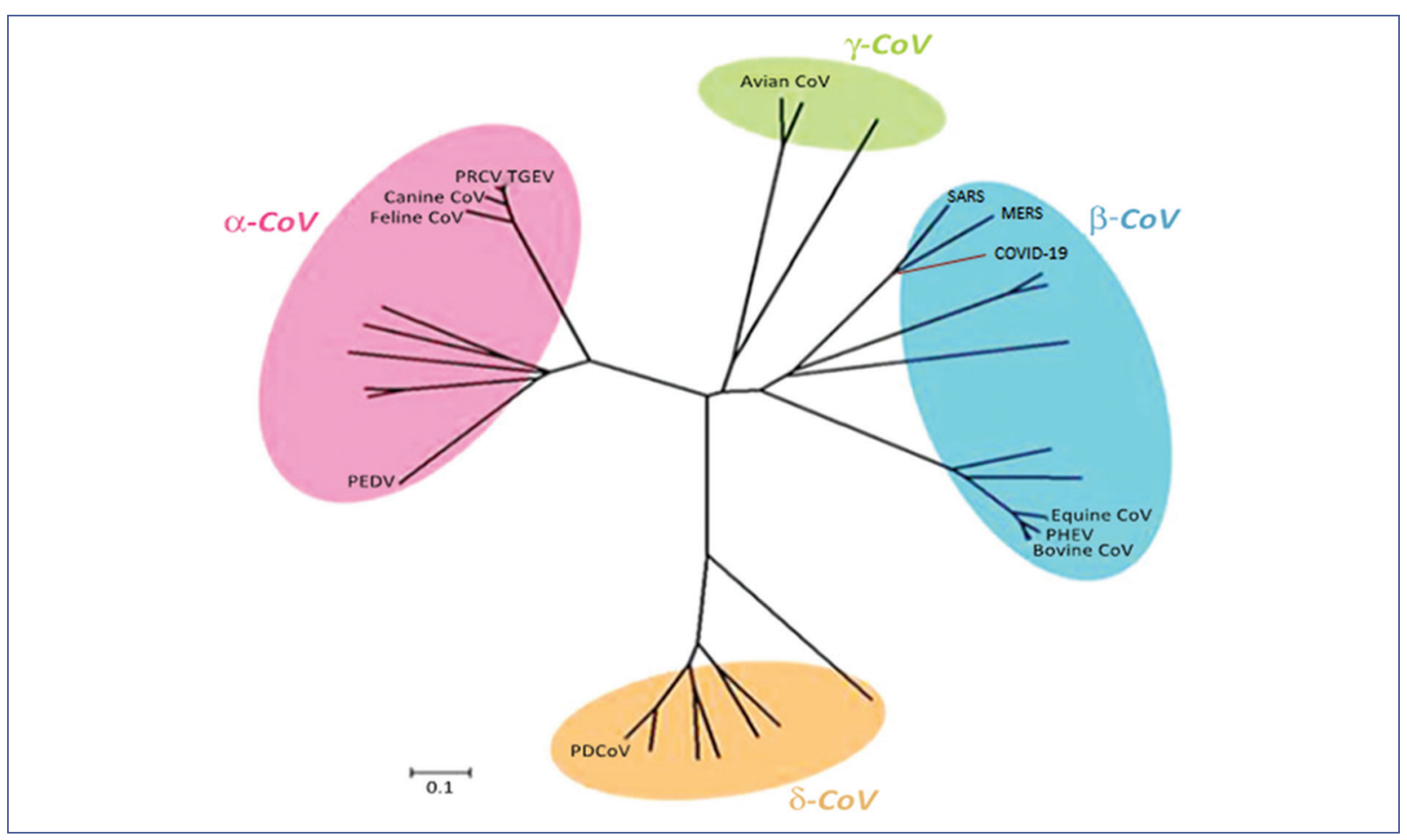

Figure 1. Coronavirus phylogenetic tree ${ }^{3}$. 


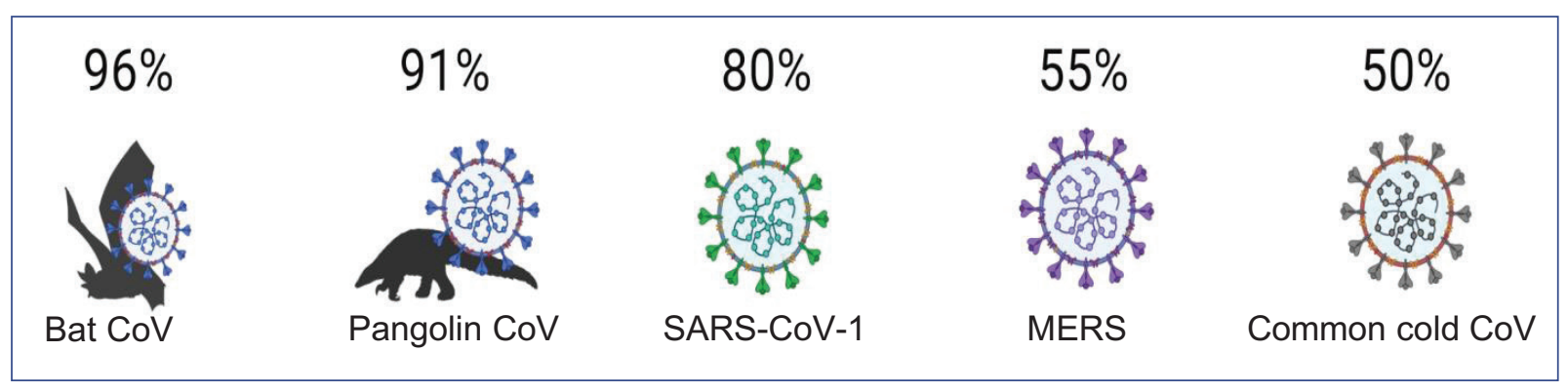

Figure 2. Coronavirus: the proportion of shared nucleotides. CoV: coronavirus; SARS-CoV-1: severe acute respiratory syndrome-type 1 coronavirus; MERS: Middle East respiratory syndrome-coronavirus. Retrieved from: https:// elifesciences.org/57309.

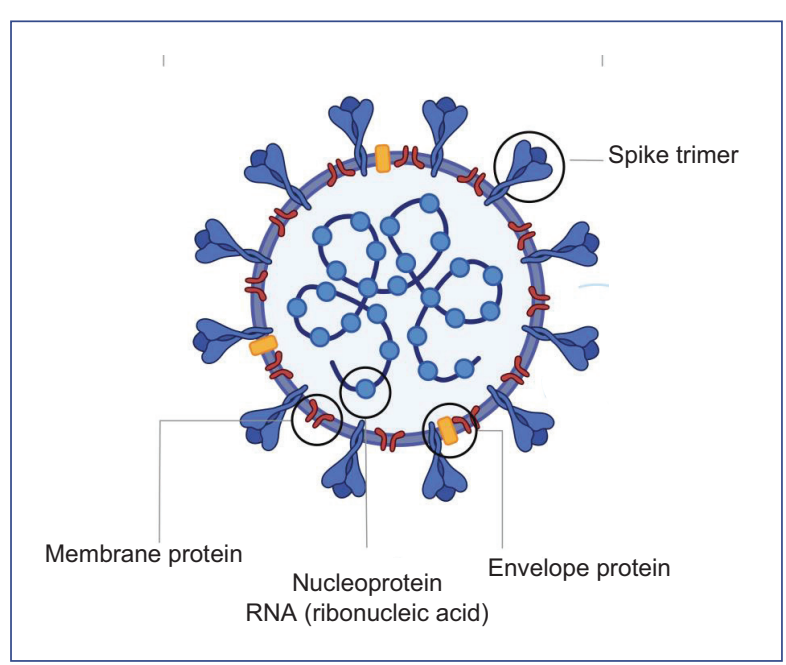

Figure 3. Structure of severe acute respiratory syndrometype 2 coronavirus. Retrieved from: https://elifesciences. org/57309.

\section{Epidemiology of CoV disease 2019}

The first case of COVID-19 was reported in the locality of Wuhan in the Hubei Province, China, on December 8, 2019. Around the last days of December, several cases were detected, including three cases of pneumonia in the same family. Thus, an initial alert was triggered for an unknown virus causing pneumonia with epidemic characteristics ${ }^{6}$.

On December 30, an active search system was established in Wuhan, and on January 10, 2020, it was declared that a different virus than SARS and MERS was causing the pneumonia cases. At this moment, the World Health Organization (WHO) was notified. Several cases of pneumonia were associated with fish, seafood, and other live animals market, and on January 7, SARSCoV-2 was identified and sequenced over the next 3 days. On January 20 , this virus was classified as class
Table 1. Cases of coronavirus disease (COVID-19) in the most affected countries (May 13, 2020)

\begin{tabular}{|l|l|l|l|l|}
\hline Place & \multicolumn{1}{|c|}{ Country } & \multicolumn{1}{|c|}{ Cases } & Deaths & Lethality (\%) \\
\hline 1 & Worldwide & $4,170,424$ & 287,399 & 6.9 \\
\hline 2 & United States & $1,430,348$ & 85,197 & 5.9 \\
\hline 3 & Spain & 271,095 & 27,104 & 9.9 \\
\hline 4 & Russia & 242,271 & 2212 & 0.9 \\
\hline 5 & United Kingdom & 229,705 & 33,188 & 14.4 \\
\hline 6 & Italy & 222,104 & 31,106 & 14.0 \\
\hline 7 & France & 178,060 & 27,074 & 15.2 \\
\hline 8 & Germany & 174,098 & 7861 & 4.5 \\
\hline 9 & Turkey & 143,114 & 3952 & 2.7 \\
\hline 11 & Iran & 112,725 & 6783 & 6.0 \\
\hline 10 & Brazil & 190,137 & 13,240 & 6.9 \\
\hline 12 & China & 82,929 & 4633 & 5.6 \\
\hline 22 & Mexico & 40,186 & 4220 & 10.5 \\
\hline
\end{tabular}

$B$ in the Chinese epidemiological notification system, with cases detected outside the city of Wuhan on January 23. As a result, on January 30 , WHO declared COVID-19 a health emergency of international concern: 7736 cases and 170 deaths had already been identified in China, while 82 cases had been detected outside China. By February 20, China reported 74,675 cases and 2121 deaths, virtually all in Wuhan; outside China, 1037 cases and eight deaths were documented.

SARS-CoV-2 was then dispersed globally. As of May 12, 4,170,424 cases and 287,399 deaths have been reported. The countries with the highest number of confirmed cases and deaths by May 13 are described in table $1^{7}$. 
Initially, all the information on COVID-19 was originated in China. However, due to the rapid spread of the virus and the accessibility of free international scientific information, clinical, epidemiological, and radiological data on this disease have been built up at a faster rate than that observed in other epidemics.

The primary strategy designed by the Chinese was the identification of confirmed cases and the total isolation of the affected cities $^{8}$. In South Korea, a strategy was designed for identifying suspected cases, as well as the confirmation of COVID-19 cases, the detection of contacts, and the compulsory isolation of cases and contacts for 14 days, which provided an opportunity to learn about the disease and efficiently control the contagion. This strategy allowed South Korea to have a lethality of $1.8 \%$, whereas it was $4.0 \%$ in China ${ }^{9}$. In other Asian countries, lethality was different: $6.2 \%$ in Iran and $1.4 \%$ in Japan. These differences fluctuated due to the strategies adopted and the infrastructure of the health services.

When COVID-19 appeared in Europe, it showed other significant differences, unlike the Asian countries. In most European countries, the adult population is proportionally high. For example, in Italy, $22 \%$ of the population is over 65 years old. In this respect, the lethality of critically ill COVID-19 patients in the 70-80-year-old group is $34 \%$ and $44 \%$ in adults $\geq 80$ years. One of the reasons considered for the high mortality rate is that Italy acted late, detecting its first patients a month after the start of the epidemic.

Furthermore, Spain has the highest life expectancy among European countries (83.4 years) but with comorbidities. It was calculated that $60 \%$ of the Spanish population aged $\geq 65$ years has at least one chronic disease, and more than one in five has a disability that impedes them from adequate incorporation into a normal lifestyle.

The lethality rate in Europe by country is $10.3 \%$ in Spain, $13.6 \%$ in Italy, $14.6 \%$ in France, and $15.6 \%$ in the United Kingdom?.

In America, the first cases were detected and confirmed in Canada and the United States. In these countries, the current case lethality rate is $5.8 \%$. Moreover, in Brazil, it is $6.9 \%$, and in Mexico, it is $9.7 \%$. The significant difference in lethality seems to be associated with the ability to detect positive cases, which has been linked to the possibility of increased testing. For example, in the USA, 5,919,847 tests have been performed (as of April 28); in Russia, 3,139,258; in Germany, 2,072,669; and in the United Arab Emirates, 1,057,326. In contrast, 77,005 tests have been performed in Mexico, and 5,791 tests in Bolivia.

\section{COVID-19 in children}

In general, it has been observed that in the population $<20$ years of age, COVID-19 is less frequent than in other age groups. It has also been described that the disease occurs more frequently in a mild to moderate form in this age group. Asymptomatic infections have been detected as well, which proportion is not completely clear ${ }^{10}$.

In a study of ten infected children in China, the persistence of SARS-CoV-2 was observed in the respiratory tract and stoo ${ }^{11}$. In a review of 44,672 patients with COVID-19, only 416 children aged $0-10$ years $(0.9 \%)$ and 549 children aged $10-19$ years (1.2\%) were found. The authors explained that the low incidence could be because children have less opportunity to come into contact with people infected with the virus ${ }^{12}$.

The most comprehensive study that has been conducted involved 2143 children ( $34.1 \%$ with confirmatory laboratory testing). The median age was 7 years, with a range of 2-13 years; most were males. The authors reported that $94.1 \%$ of the cases were asymptomatic, mild, or moderate. Of the severe cases, 112 were children $(5.2 \%)$, only 13 patients $(0.6 \%)$ were critical, and only one 14-year-old male patient died ${ }^{13}$.

Evidence suggests that children are less affected than adults, for which the differences between China and European countries should be noticed, as well as the effect that may happen in countries where the population pyramids of children under 20 years predominate.

In Mexico, the affected population < 14 years of age represents $1 \%$ of the confirmed cases, with only 11 deaths as of May $13^{14}$.

\section{Status of COVID-19 in Mexico}

In Mexico, there is a similar growth trend in the epidemic in comparison to other countries such as the Philippines and Poland up to April 6 (Fig. 4). Initially, the cases discovered were imported, mostly from the United States, Italy, and Spain, and individuals who had contact with migrants from those countries. Subsequently, there was a local dissemination.

As of May 14, 42,595 cases and 4477 deaths had been reported. A total of $58 \%$ of the cases were male, and the most affected age groups are those between 30 and 70 years ( $80 \%$ of the cases). Individuals under 20 years old represent only $12 \%$ of the cases, and $21 \%$ are over 60 years old. The overall lethality rate so far is $10.5 \%$. Unfortunately, it is higher in people over 65 , but fortunately very low in children. Of the population that has died, $55 \%$ were between 40 and 59 years of 


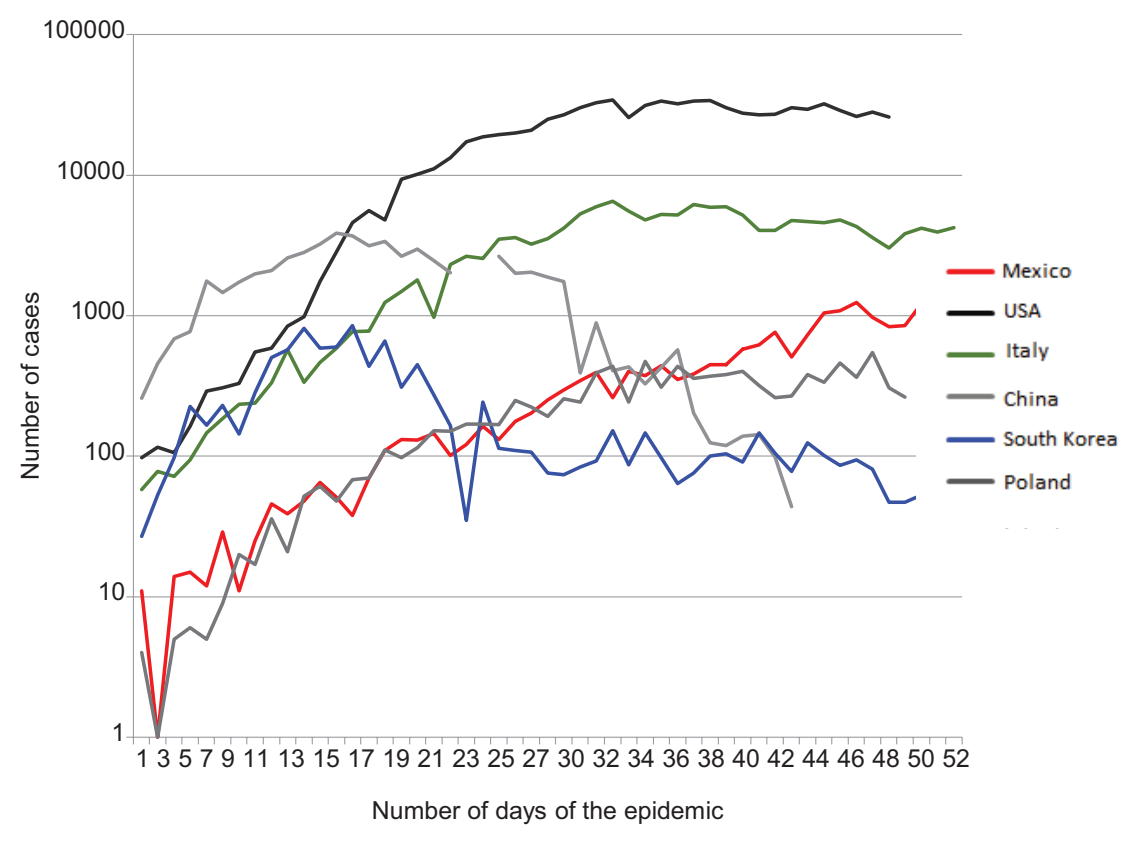

Figure 4. COVID-19 case trends in selected countries, based on early days of the pandemic (April 30, 2020).

Table 2. Cases and deaths due to coronavirus disease (COVID-19), according to comorbidity (Mexico, April 20, 2020)

\begin{tabular}{|l|c|c|c|}
\hline Comorbidity & Cases & Deaths & Lethality (\%) \\
\hline Arterial hypertension & 3,640 & 683 & 18.8 \\
\hline Obesity & 3,493 & 477 & 13.7 \\
\hline Diabetes & 3,064 & 618 & 20.2 \\
\hline Smoking & 1,496 & 150 & 10.0 \\
\hline Asthma & 585 & 48 & 8.2 \\
\hline Cardiovascular disease & 473 & 107 & 22.6 \\
\hline $\begin{array}{l}\text { Chronic obstructive } \\
\text { pulmonary disease }\end{array}$ & 421 & 114 & 27.1 \\
\hline Chronic kidney disease & 388 & 107 & 27.6 \\
\hline
\end{tabular}

SSA/DGE/Datos Abiertos: 20050430COVID19MEXIC0.csV

age, $6.8 \%$ were $<40$ years of age, and $37.9 \%$ were $\geq 60$ years of age ${ }^{11}$. These percentages contrast with the observations in Italy and China, where mortality is higher in the population $\geq 65$ years. In order of importance, the comorbidities associated with deaths are high blood pressure, obesity, diabetes, smoking, chronic obstructive pulmonary disease, chronic kidney disease, cardiovascular disease, and asthma.
In Mexico, there were 16,906 hospitalized cases of COVID-19 as of May 14, of which $75 \%$ developed pneumonia and $11 \%$ required intubation ${ }^{14}$.

In Mexico, the projection about the behavior of the disease and mortality associated with comorbidities is different from that of other countries because Mexico occupies the first place in obesity, child obesity, and diabetes. In addition, the population is predominantly children and young people (Table 2).

In Mexico, the defined strategy comprises isolation and social distancing, staying home, and only taking $100 \%$ of the samples of severe cases and $10 \%$ of the suspicious cases in sentinel locations in the country, which will only allow having an idea of what will happen without knowing the total number of cases. Simultaneously, the contacts of the infected people are monitored and isolated. So far, the response capacity of the health system has been maintained because the strategy in Mexico is to preserve flattened transmission to avoid saturation of health services, regardless of a longer ongoing epidemic as a result.

\section{The natural history of COVID-19}

\section{Pre-pathogenic period}

SARS-CoV-2 is genetically almost identical to SARS$\mathrm{CoV}$ found in a bat species (Fig. 2). Although a 
SARS-CoV-2-like CoV has been found in pangolin, recent studies determined a lower proportion of nucleotides than initially reported. Although SARS-CoV-2 has been identified in dogs, cats, and some Felidae members in a zoo, it is not known if these species could serve as a reservoir of $\mathrm{CoV}$ and transmit it as a zoonosis ${ }^{15}$.

Person-to-person transmission of SARS-CoV-2 is known to occur through the Flügge droplets from the mouth and nose when a person coughs, sneezes, speaks, or breathes. It was initially thought that this virus could spread within $1.5 \mathrm{~m}$ of the transmitting person and that it would precipitate to the ground or various surfaces, remaining for hours in aluminum and up to 5 days in plastics ${ }^{16}$. Recently, some studies reported that particles could remain in the air for several hours and be transmitted to humans ${ }^{17}$. Although the virus has been detected in feces and semen, the potential for transmissibility in these mediums is unknown ${ }^{18}$.

It has been estimated that a sick person could infect $\mathrm{R}_{\mathrm{o}}$ 2-4 individuals within $1.5 \mathrm{~m}^{19}$.

\section{Pathogenic period}

This phase comprises the incubation period of the virus, which is of 5 days on average and ranges from 0 to 14 days $^{20}$. Around the past 2 days of the incubation period, viremias are already present and, therefore, virus transmission. A proportion of asymptomatic patients has also been found, who can transmit SARS-CoV-2 21 .

According to observations in China, about $80 \%$ of infected people with COVID-19 may develop mild to moderate clinical symptoms, be treated on an outpatient basis, and recover in an average of 2 weeks; in these cases, the most common symptoms are dry cough, fever $\geq 38^{\circ} \mathrm{C}$, and general malaise ${ }^{16}$.

Furthermore, $15 \%$ of positive patients may have a severe clinical picture characterized by dry cough, sore throat, fever $\geq 38^{\circ} \mathrm{C}$, and dyspnea, but most of them usually recover within 6 weeks. Generally, these patients do not require intensive care.

Finally, 5\% of those infected with SARS-CoV-2 develop a critical illness, and require management in intensive care units because of variable degrees of pneumonia in addition to other complications. These patients may need intubation or tracheotomy and automatic ventilators. According to the $\mathrm{WHO}$, the lethality in this group of patients is about $5.4 \%$, with a range between $0.2 \%$ and $12.3 \%$. Mortality is related to a high viral load and its association with comorbidities.
The current situation within countries, the speed at which new infections are occurring, and the demands for hospitalization have forced the analysis of various therapeutic measures, some empirical and other based on the response to previous epidemics by different CoVs. It is essential to identify and critically analyze the sources of information to make the best decisions and maintain the principles of justice and nonmaleficence.

\section{Hydroxychloroquine and the hydroxychloroquine/azithromycin combination in the treatment of COVID-19}

Globally, there is a need for specific treatment against SARS-CoV-2, due to the morbidity and severity that some COVID-19 patients show. Different antivirals and immunomodulators are currently under evaluation. Maybe due to its accessibility and lower cost or because it is a "better known" drug and solely based on a French article $^{22}$, the prescription of chloroquine (ideally, hydroxychloroquine) was diffused and even recommended in various treatment guidelines. In this sense, there has been an effervescence in the use of the hydroxychloroquine/azithromycin combination.

A history of in vitro studies showing that chloroquine reduces the viral replication of CoVs such as SARS-CoV and MERS-CoV motivated its evaluation with SARSCoV-2, where evidence of replication inhibition was found ${ }^{23}$. In China, a preliminary evaluation of the administration of hydroxychloroquine to 100 patients with COVID-19 was conducted. Since the results showed clinical and radiological improvement of the disease, clearance of the virus, and shortening of the evolution of the disease, the findings appeared promising ${ }^{24}$. Unfortunately, this is the only clinical information that has been reported in an article, without any further analysis that would give sufficient power to the claims. As the pandemic has progressed, doubts have grown about the real usefulness of chloroquine and hydroxychloroquine, and a series of clinical trials have been initiated with no results yet available. At a meeting in China on February 15,2020 , the authors of 15 ongoing clinical studies, along with government authorities, concluded that chloroquine showed good activity against COVID-19 and recommended that it can be included in their Guide to the Prevention, Diagnosis, and Treatment of COVID-19 Pneumonia. Several studies are currently in progress, the first in China and more recently in other parts of the world, but there are still no results to claim that it is a useful treatment option. The controlled studies that will allow further recommendations are derived from a 
clinical trial of the use of hydroxychloroquine as prophylactic therapy in patients exposed to confirmed infected persons and from a study regarding the management of mild to moderate forms of SARS-Cov-2 infection; in both studies, no difference was observed when compared to groups receiving placebo ${ }^{25,26}$. The usefulness of chloroquine or hydroxychloroquine, with or without azithromycin, has not been endorsed or ruled out in controlled clinical trials in critically ill or severe patients.

So far, the administration of chloroquine and hydroxychloroquine can be considered experimental; consequently, the Ethics Committees of the institutions should approve this prescription. The argument for prescribing these drugs is based on the risk-benefit ratio; however, for adult patients, the benefit is uncertain. Furthermore, due to the toxic effects of both chloroquine and hydroxychloroquine, the administration of these drugs implicates some risks, especially when considering a high percentage of patients with comorbidities who simultaneously require other drugs, which are contraindicated with the two mentioned above.

The use of chloroquine and hydroxychloroquine at the hospital level may allow for early detection of some of the adverse effects. However, widespread media coverage and over-prescription, even as a prophylactic (for which it is not useful) ${ }^{23}$, put the outpatient population at risk. During the pandemic, cases of death from chloroquine poisoning have already been reported.

The adult group is the most affected by COVID-19, for which the experience in using these drugs in children is still minimal. Therefore, the use of chloroquine and hydroxychloroquine in children should be discussed by Clinical and Ethics Committees and used compassionately. Furthermore, no dose can be extrapolated in the treatment of children with COVID-19. There is no basis for considering that the dosage used in malaria can be adjusted to children with this disease.

The combination of azithromycin and hydroxychloroquine was expanded due to the wide diffusion in social media, where the document was even circulating before its publication (an article by a group of researchers from Marseille, France ${ }^{25}$ ). Dahly et al., in the United Kingdom, conducted a detailed analysis of the biases and methodological problems of this paper ${ }^{27}$. It should be noted that the clinical characteristics of the six patients who received the combination of drugs are not known in detail, nor is their state of health or the clinical form of the infection. The outcome evaluation is focused on viral clearance in the nasopharynx, with what the authors consider the patient "cured." As commented by
Table 3. Use of corticosteroids in severe lung infections

\begin{tabular}{|c|c|}
\hline $\begin{array}{l}\text { Disease or } \\
\text { infection }\end{array}$ & $\begin{array}{l}\text { Effects observed with corticosteroid treatment: } \\
\text { hydrocortisone, methylprednisolone, } \\
\text { dexamethasone, and prednisolone }\end{array}$ \\
\hline MERS-CoV & $\begin{array}{l}\text { Delayed viral clearance in the respiratory tract } \\
\text { Adjusted risk ratio } 0-4(95 \% \mathrm{Cl} 0-2-0-7) \mathrm{CoV}\end{array}$ \\
\hline SARS-CoV & $\begin{array}{l}\text { Delayed viral clearance in the blood } \\
\text { Reported as a significant difference without } \\
\text { calculation of the effect size }\end{array}$ \\
\hline SARS-CoV & $\begin{array}{l}\text { Psychosis, associated with an increase in the } \\
\text { accumulated dose: } 10.9 \mathrm{~g} \text { vs. } 6.7 \mathrm{~g} \text { of the } \\
\text { hydrocortisone equivalent, is presented as an } \\
\text { adverse effect }\end{array}$ \\
\hline SARS-CoV & $\begin{array}{l}\text { 33/95 patients who received corticosteroids had } \\
\text { secondary diabetes }\end{array}$ \\
\hline SARS-CoV & $\begin{array}{l}\text { Of } 40 \text { patients who survived, } 12(30 \%) \text { had } \\
\text { avascular necrosis and } 30(75 \%) \text { osteoporosis }\end{array}$ \\
\hline Influenza & $\begin{array}{l}\text { Evidence from a meta-analysis of } 10 \text { studies with } \\
6548 \text { patients indicates increased mortality } \\
\text { Risk ratio: } 1-75(95 \% \mathrm{Cl} 1-3-2-4, p=0.0002)\end{array}$ \\
\hline $\begin{array}{l}\text { Respiratory } \\
\text { syncytial virus }\end{array}$ & $\begin{array}{l}\text { A controlled clinical trial with } 600 \text { children: no } \\
\text { clinical benefit was observed in the group } \\
\text { receiving corticosteroids ( } 305 \text { patients) } \\
\text { An observational study: } 33 / 50 \text { adults received } \\
\text { corticosteroids. There was no benefit, but an } \\
\text { altered antibody response was found }\end{array}$ \\
\hline
\end{tabular}

$\mathrm{Cl}$ : confidence interval; CoV: Coronavirus; MERS: Middle East respiratory syndrome; SARS: severe acute respiratory syndrome.

Adapted from: Russell et al. Clinical evidence does not support corticosteroid treatment for 2019-nCoV lung injury. Lancet. 2020;395:473-5.

the authors, "in reality, a series of six cases are presented whose strength must be adequately weighted."

Definitively, this study cannot be taken as an endorsement for prescribing this combination of drugs ${ }^{27}$. The findings are significant, but controlled clinical trials should be conducted to help in making better clinical decisions. Again, the treated cases correspond to adult patients, so pediatricians should not be tempted to make this prescription until it is endorsed by committees that strictly consider the potential risk to which children would be subjected.

\section{Use of corticosteroids for the treatment of SARS-CoV-2 disease}

At present, there is no internationally approved treatment for COVID-19 disease. The available information has been obtained through testing different types of CoVs and from in vitro activity or clinical trials using drugs under compassionate use or used as a last line 
of management. Corticosteroids have been used for a variety of infections in epidemic situations ${ }^{28}$. The WHO Clinical Management Guidelines ${ }^{6}$ state that corticosteroids should not be prescribed unless there is another indication for their use (e.g., septic shock). However, these medications have been used in an attempt to decrease the inflammation responsible for lung damage. Russell et al. reviewed some significant studies that record the effects of corticosteroid treatment in severe lung infections ${ }^{28}$ (Table 3). Most studies report no difference in mortality between patients receiving corticosteroids compared to those not receiving them, and several of the results point to a detrimental effect of corticosteroid use. Some adverse effects are directly related to the presence of the virus in the respiratory tract $^{29}$ or bloodstream ${ }^{30}$, while others are related to the activity of the drug in different organs ${ }^{31}$. There is more evidence against its use under two conditions. The first is influenza, as shown by $\mathrm{Ni}$ et al. ${ }^{32}$ in a systematic review and meta-analysis, in which they found an increase in mortality. The second is bronchiolitis due to respiratory syncytial virus, in which no benefit of treatment was found neither in children ${ }^{33}$ nor in adults ${ }^{34}$.

In response to the review by Russell et al. ${ }^{28}$, a group of Chinese physicians considered that for $\mathrm{CoV}$ infection, the evidence comes mostly from observational studies ${ }^{35}$. Therefore, it cannot be concluded that corticosteroids cause more harm than benefit. Shang et al. remark that adverse effects were found in only three SARS-CoV studies. However, in at least 25 other published studies adverse effects were not found, although the evidence is not sufficient to recommend the use of corticosteroids. In a retrospective study of 401 SARS patients, mortality and days of hospitalization decreased, and no other complications were observed ${ }^{36}$. In a prospective cohort of 2141 patients with H1N1pdm09 influenza from 407 hospitals in China, a low-moderate dose (25-150 mg/day) of methylprednisolone (or an equivalent) reduced the mortality in patients with Kirby index $<300 \mathrm{mmHg}^{37}$.

Regarding the existing controversy about the use of corticosteroids in COVID-19, experts from the Chinese Thoracic Society ${ }^{38}$ developed a consensus with the following recommendations:

1. The risk-benefit balance should be carefully evaluated before using corticosteroids, always seeking to obtain the most significant benefit.

2. Corticosteroids should be used with caution in patients with severe SARS-CoV-2 pneumonia.

3. For patients with hypoxemia due to underlying disease, or who routinely use corticosteroids for chronic disease, these steroids should be used with caution.
4. Doses should be low to moderate $(\leq 0.5-1 \mathrm{mg} / \mathrm{kg} / \mathrm{day}$ of methylprednisolone or equivalent) and for a short duration ( $\leq 7$ days).

Since the information from systematic reviews and meta-analyses has not reached the same conclusion, unrestricted use of steroids is not recommended. However, if necessary, the administration should be at low doses and for a short period, and side effects should be monitored as well.

\section{Use of antihypertensive drugs related to the renin-angiotensin axis}

The renin-angiotensin-aldosterone (RAA) axis has been linked to the mechanism of COVID-19 infection. Under normal conditions, angiotensinogen, a glycoprotein produced mainly in the liver, is converted into angiotensin I (AT-I) by renin (an enzyme produced by the juxtaglomerular cells of the kidney). AT-I properties favor vasodilation through the production of nitric oxide (NO) and bradykinins. Subsequently, angiotensin-converting enzyme (ACE), which is secreted in the kidney, lung, and central nervous system, and blocked by the family of ACEinhibiting (ACEi) antihypertensive drugs, converts AT-I into angiotensin II (AT-II), which has an affinity for the following two receptors ${ }^{39}$ :

1. Angiotensin type 1 receptor (AT1R) causes vasoconstriction and increases blood pressure through the release of aldosterone; it is the therapeutic flank of AT-Il receptor blocking (ARBs) drugs.

2. Angiotensin type 2 receptor (AT2R) has properties for regulating angiogenesis and apoptosis.

Furthermore, ACE-2 is produced in various organs (lung, heart, epididymis, intestine, and central nervous system). In these organs, ACE-2 converts AT-I to angiotensin (1-9), which has a more significant vasodilator effect and maintains the structure of the intima layer of the small vessels. Also, ACE-2 converts AT-II to angiotensin (1-7), which has antiproliferative, antiapoptotic, and antiatherogenic activity ${ }^{40}$.

SARS-CoV-2 expresses a protein along its surface called S-protein, which has an affinity for the components of ACE- $2^{41}$. Their binding favors endocytosis of the virus in the pulmonary epithelium, generating one of the main mechanisms of virulence. Based on the these interactions, several hypotheses regarding the use of antihypertensives have been proposed:

1. The effect of COVID-19 infection on the RAA axis ${ }^{42,43}$. ACE-2 physiological activity generates end-products that maintain vasodilation in vessels and capillaries and regulate the effects mediated by the activation of 
AT1R via ACE. So far, COVID-19 behavior has shown that those subjects who manifest severe pulmonary complications evolve with a clinical pulmonary arterial hypertension phenotype similar to that of group III WHO classification (secondary to lung injury), demonstrating a decreased production of NO, fibrosis, and increased activation of neutrophils. This fact seems to be explained by the inactivation of the ACE-2 pathway because SARS-CoV-2 uses it for its virulence. Whether the ACE/ACE2 ratio has a direct causal association with the infection susceptibility or a prognostic role in patients is currently not known. Delanghe et al. conducted an ecological study evaluating the epidemiological behavior of infections by country and its relationship with the population expression of ACE polymorphisms, finding that countries with overexpression represent $38 \%\left(r^{2}=0.38\right)$ of infections and $50 \%\left(r^{2}=0.50\right)$ of deaths $s^{44}$.

2. The possible interaction with antihypertensive drugs ${ }^{45}$. In all countries, systemic arterial hypertension has been identified as the comorbidity most associated with COVID19 and the development of lethal complications. Laboratory studies in animals showed that the use of RAA inhibitor drugs could increase up to $40 \%$ the production of ACE-2 and favor the entry of COVID-19. However, cohort studies conducted in Wuhan $\mathrm{City}^{46}$ found no difference when comparing the group of survivors and non-survivors with a history of medication with ACEi or ARBs drugs ${ }^{46}$. Similarly, Zhang et al. analyzed a cohort of hypertensive patients with COVID-19 ( $n=1128)$, comparing the use of ARBs/ACEi versus other types of medication. The authors found a protective role for mortality in a multivariate analysis (adjusted for variables such as sepsis, acute respiratory failure, renal, and cardiac failure $)^{43}$. Previously, a meta-analysis of 37 articles (quasi-experimental, randomized clinical trials, and intervention cohorts) that evaluated ARBs/ACEi therapy in cases of viral pneumonia was published, finding a protective effect (odds ratio $[\mathrm{OR}]=0.66,95 \%$ confidence interval [Cl] 0.55-0.80) for infection and an association with lower mortality ${ }^{47}$.

3. COVID-19, the RAA axis, and pediatric patients. An initial theory described that a lower expression of ACE-2 could explain the lower frequency of infection and severe symptoms in childhood. However, Schouten et al. ${ }^{48}$ could not demonstrate that enzyme levels changed with age. The review of cohort studies in infected pediatric populations did not demonstrate factors related to hypertension and the association of drugs with mortality; notably, there is no evidence reported of outcomes in populations with congenital heart disease $\mathrm{e}^{42,49}$.

4. Currently, one possible treatment is the use of ACE-2 analog drugs, which are in phase 2 clinical trials. In animal models, a decrease in interleukin- 6 levels, an increase in lung surfactant concentration, and the binding to SARS-COV-2 protein $S$, neutralizing its invasion process, have been shown. ${ }^{39}$

So far, there is no evidence that the suspension of ARBs/ACEi drugs prevents infection by the new CoV, nor should infected subjects be deprived of the effectiveness of these drugs in preventing the development of major cardiovascular events and their possible regulatory relationship with the harmful effects of the virus on the pulmonary parenchyma.

This review mentions only some of the aspects that have emerged during this pandemic. The emergence of a new virus has made it possible to observe the epidemiological behavior in different populations, races, age groups, nutritional status conditions, the prevalence of comorbidities in the population, and customs, among other characteristics. The accessibility of scientific and non-scientific information on social media has led to the inclusion of therapeutic decisions that are not entirely justified but are often supported by the "compassionate use of drugs." Many other controversies require a better analysis, such as the widespread use of masks, the impact of conducting more tests, and the best time to recommend social distancing to avoid a case outbreak. Finally, many questions that require future analysis remain.

\section{Ethical disclosures}

Protection of human and animal subjects. The authors declare that no experiments were performed on humans or animals for this study.

Confidentiality of data. The authors declare that they have followed the protocols of their work center on the publication of patient data.

Right to privacy and informed consent. The authors have obtained the written informed consent of the patients or subjects mentioned in the article. The corresponding author is in possession of this document.

\section{Conflicts of interest}

The authors declare that they have no conflicts of interest. 


\section{Funding}

None.

\section{References}

1. Li Q, Guan X, Wu P, Wang X, Zhou L, Tong Y, et al. Early transmission dynamics in Wuhan, China, of novel coronavirus-infected pneumonia. $\mathrm{N}$ Engl J Med. 2020;382:1199-207.

2. Meo SA, Alhowikan AM, Al-Khlaiwi T, Meo IM, Halepoto DM, Iqbal M, et al. Novel coronavirus 2019-nCoV: prevalence, biological and clinical characteristics comparison with SARS-CoV and MERS-CoV. Eur Rev Med Pharmacol Sci. 2020;24:2012-9.

3. Wang L. Animal Coronavirus. New York: Springer; 2016. Available from: https://www.springer.com/gp/book/9781493934126.

4. Guarner J. Three emerging coronaviruses in two decades. Am J Clin Pathol. 2020;153:420-1.

5. Bar-On YM, Flamholz A, Phillips R, Milo R. SARS-CoV-2 (COVID-19) by the numbers. Elife. 2020;9:1-15

6. World Health Organization. Clinical Management of Severe Acute Respiratory Infection When Novel Coronavirus (nCoV) Infection is Suspected. Geneva: World Health Organization; 2020. Available from: https://www. apps.who.int/iris/handle/10665/331446.

7. Worldometer. United States of America: coronavirus. Available from: https://www.worldometers.info/coronavirus.

8. Wu Z, McGoogan JM. Characteristics of and important lessons from the coronavirus disease 2019 (COVID-19) outbreak in China: summary of a report of 72314 cases from the Chinese center for disease control and prevention. JAMA. 2020;323:1239-42.

9. Shim E, Tariq A, Choi W, Lee Y, Chowell G. Transmission potential and severity of COVID-19 in South Korea. Int J Infect Dis. 2020;93:339-44.

10. Lee PI, Hu YL, Chen PY, Huang YC, Hsueh PR. Are children less susceptible to COVID-19? J Microbiol Immunol Infect. 2020;53:371-2.

11. Cai J, Xu J, Lin D, Yang Z, Xu L, Qu Z, et al. A case series of children with 2019 novel coronavirus infection: clinical and epidemiological features. Clin Infect Dis. 2020;2020;1-17.

12. Epidemiology Working Group for NCIP Epidemic Response, Chinese Center for Disease Control and Prevention. The epidemiological characteristics of an outbreak of 2019 novel coronavirus diseases (COVID-19) in China. Zhonghua Liu Xing Bing Xue Za Zhi. 2020;41:145-51.

13. Dong $Y$, Mo X, Hu Y, Qi X, Jiang F, Jiang Z, et al. Epidemiology of COVID-19 among children in China. Pediatrics. 2020;145:1-10.

14. Secretaría de Salud. México: datos Abiertos-dirección General de Epidemiología. Available from: https://www.gob.mx/salud/documentos/datos-abiertos-152127.

15. Centers for Disease Control and Prevention. United States of America: coronavirus Disease 2019 (COVID-19), Frequently Asked Questions. Available from: https://www.cdc.gov/coronavirus/2019-ncov/faq.html.

16. Jin $\mathrm{Y}$, Yang H, Ji W, Wu W, Chen S, Zhang W, et al. Virology, epidemiology, pathogenesis, and control of COVID-19. Viruses. 2020;12:1-17.

17. Chen C, Gao G, Xu Y, Pu L, Wang Q, Wang L, et al. SARS-CoV-2-positive sputum and feces after conversion of pharyngeal samples in patients with COVID-19. Ann Intern Med. 2020;172:832-4.

18. Li D, Jin M, Bao P, Zhao W, Zhang S. Clinical characteristics and results of semen tests among men with coronavirus disease 2019. JAMA Netw Open. 2020;3:1-3

19. Liu Y, Gayle AA, Wilder-Smith A, Rocklov J. The reproductive number of COVID-19 is higher compared to SARS coronavirus. J Travel Med. 2020;27:1-4.

20. Lauer SA, Grantz KH, Bi Q, Jones FK, Zheng Q, Meredith HR, et al. The incubation period of coronavirus disease 2019 (COVID-19) from publicly reported confirmed cases: estimation and application. Ann Intern Med. 2020;172:577-82

21. Rothe C, Schunk M, Sothmann P, Bretzel G, Froeschl G, Wallrauch C, et al. Transmission of 2019-nCoV infection from an asymptomatic contact in Germany. N Engl J Med. 2020;382:970-1.

22. Gautret $P$, Lagier JC, Parola $P$, Hoang VT, Meddeb L, Mailhe M, et al. Hydroxychloroquine and azithromycin as a treatment of COVID-19: results of an open-label non-randomized clinical trial. Int $\mathrm{J}$ Antimicrob Agents. 2020;56:105949.

23. Colson P, Rolain JM, Raoult D. Chloroquine for the 2019 novel coronavirus SARS-CoV-2. Int J Antimicrob Agents. 2020;55:1-2.

24. Wang M, Cao R, Zhang L, Yang X, Liu J, Xu M, et al. Remdesivir and chloroquine effectively inhibit the recently emerged novel coronavirus (2019-nCoV) in vitro. Cell Res. 2020;30:269-71.

25. Boulware DR, Pullen MF, Bangdiwala AS, Pastick KA, Lofgren SM, Okafor EC, et al. A randomized trial of hydroxychloroquine as postexpo- sure prophylaxis for Covid-19. N Engl J Med. 2020;383:517-25

26. Tang W, Cao Z, Han M, Wang Z, Chen J, Sun W, et al. Hydroxychloroquine in patients with mainly mild to moderate coronavirus disease 2019: open-label, randomised controlled trial. BMJ. 2020;369:1-11.

27. Dahly D, Gates S, Morris T. Statistical Review of Hydroxychloroquine and Azithromycin as a Treatment of COVID-19: results of an Open-label Non-Randomized Clinical Trial. Trial Methodology Research Network: 2020. Available from: https://www.zenodo.org/record/3724167\#.XvkC5kVKiUk.

28. Russell CD, Millar JE, Baillie JK. Clinical evidence does not support corticosteroid treatment for 2019-nCoV lung injury. Lancet. 2020;395:473-5.

29. Arabi YM, Mandourah Y, Al-Hameed F, Sindi AA, Almekhlafi GA, Hussein MA, et al. Corticosteroid therapy for critically III patients with middle east respiratory syndrome. Am J Respir Crit Care Med. 2018;197:757-67.

30. Lee N, Chan KC, Hui DS, Ng EK, Wu A, Chiu RW, et al. Effects of early corticosteroid treatment on plasma SARS-associated coronavirus RNA concentrations in adult patients. J Clin Virol. 2004;31:304-9.

31. Lee DT, Wing YK, Leung HC, Sung JJ, Ng YK, Yiu GC, et al. Factors associated with psychosis among patients with severe acute respiratory syndrome: a case-control study. Clin Infect Dis. 2004;39:1247-9.

32. Ni YN, Chen G, Sun J, Liang BM, Liang ZA. The effect of corticosteroids on mortality of patients with influenza pneumonia: a systematic review and meta-analysis. Crit Care. 2019;23:1-9.

33. McGee S, Hirschmann J. Use of corticosteroids in treating infectious diseases. Arch Intern Med. 2008;168:1034-46.

34. Corneli HM, Zorc JJ, Mahajan P, Shaw KN, Holubkov R, Reeves SD, et al. A multicenter, randomized, controlled trial of dexamethasone for bronchiolitis. N Engl J Med. 2007;357:331-9.

35. Shang L, Zhao J, Hu Y, Du R, Cao B. On the use of corticosteroids for 2019-nCoV pneumonia. Lancet. 2020;395:683-4.

36. Chen RC, Tang XP, Tan SY, Liang BL, Wan ZY, Fang JQ, et al. Treatment of severe acute respiratory syndrome with glucosteroids: the Guangzhou experience. Chest. 2006;129:1441-52.

37. Li H, Yang SG, Gu L, Zhang Y, Yan XX, Liang ZA, et al. Effect of low-to-moderate-dose corticosteroids on mortality of hospitalized adolescents and adults with influenza A(H1N1)pdm09 viral pneumonia. Influenza Other Respir Viruses. 2017;11:345-54.

38. Zhao JP, Hu Y, Du RH, Chen ZS, Jin Y, Zhou M, et al. [Expert consensus on the use of corticosteroid in patients with 2019-nCoV pneumonia]. Zhonghua Jie He He Hu Xi Za Zhi. 2020;43:183-4.

39. Buckley LF, Cheng JW, Desai A. Cardiovascular pharmacology in the time of COVID-19: a focus on angiotensin-converting enzyme 2. J Cardiovasc Pharmacol. 2020;75:526-9.

40. Dalan R, Bornstein SR, El-Armouche A, Rodionov RN, Markov A, Wielockx B, et al. The ACE-2 in COVID-19: foe or friend? Horm Metab Res. 2020;52:257-63

41. Dhawan R, Gundry RL, Brett-Major DM, Mahr C, Thiele GM, Lindsey ML, et al. COVID-19 and cardiovascular disease: what we know, what we think we know, and what we need to know. J Mol Cell Cardiol. 2020;144:12-4

42. Guo J, Huang Z, Lin L, Lv J. Coronavirus disease 2019 (COVID-19) and cardiovascular disease: a viewpoint on the potential influence of angiotensin-converting enzyme inhibitors/angiotensin receptor blockers on onset and severity of severe acute respiratory syndrome coronavirus-2 infection. J Am Heart Assoc. 2020;9:1-5.

43. Zhang P, Zhu L, Cai J, Lei F, Qin JJ, Xie J, et al. Association of inpatient use of angiotensin-converting enzyme inhibitors and angiotensin II receptor blockers with mortality among patients with hypertension hospitalized with COVID-19. Circ Res. 2020;126:1671-81.

44. Delanghe JR, Speeckaert MM, De Buyzere ML. The host's angiotensin-converting enzyme polymorphism may explain epidemiological findings in COVID-19 infections. Clin Chim Acta. 2020;505:192-3.

45. Sarzani R, Giulietti F, Di Pentima C, Giordano P, Spannella F. Severe acute respiratory syndrome coronavirus-2 infection, angiotensin-converting enzyme 2 and treatment with angiotensin-converting enzyme inhibitors or angiotensin II type 1 receptor blockers. Eur J Prev Cardiol. 2020;2020:1-4.

46. Li J, Wang X, Chen J, Zhang H, Deng A. Association of renin-angiotensin system inhibitors with severity or risk of death in patients with hypertension hospitalized for coronavirus disease 2019 (COVID-19) infection in Wuhan, China. JAMA Cardiol. 2020;5:E1-6.

47. Caldeira D, Alarcao J, Vaz-Carneiro A, Costa J. Risk of pneumonia associated with the use of angiotensin-converting enzyme inhibitors and angiotensin receptor blockers: systematic review and meta-analysis. BMJ. 2012;345:1-20.

48. Schouten LR, van Kaam AH, Kohse F, Veltkamp F, Bos LD, de Beer FM, et al. Age-dependent differences in pulmonary host responses in ARDS: a prospective observational cohort study. Ann Intensive Care. 2019:9:1-9.

49. Verdecchia P, Reboldi G, Cavallini C, Mazzotta G, Angeli F. ACE-inhibitors, angiotensin receptor blockers and severe acute respiratory syndrome caused by coronavirus. G Ital Cardiol (Rome). 2020;21:321-7. 